\title{
The sorting of workers across job tasks: an application to graduates and occupational choice
}

\author{
Stijn Rocher* \\ University of Antwerp
}

\begin{abstract}
In this paper, workers are assumed to acquire task-specific skills prior to labor market entry. The theoretical framework on tasks assumes that workers sort across jobs based on comparative advantage in tasks. I derive three propositions of this conceptual framework which are verified empirically. I find that (i) major choice is an important determinant of what tasks workers do at their job; (ii) graduates majored in the same field self-select into occupations with similar task content and (iii) also the wages of these graduates is correlated strongest when they do similar tasks.
\end{abstract}

Keywords: Job tasks, task-specific skills, occupational choice

\section{Introduction}

The traditional view on human capital distinguishes between two types of skills: general-purpose skills and form-specific skills. A part of the worker's skill bundle may only be of value in their current form and therefore firm-specific. In contrast to firm-specific skills, workers also possess general-purpose skills useful to a variety of firms. Becker (1964) and Mincer (1974) pioneered to provide a theoretical underpinning of this two-sided notion of human capital. This human capital theory can explain why wages rise significantly with job tenure (Brown, 1989; Topel, 1991). Other key predictions in line with facts about wages and tenure are that turnover (like quits and layoffs) decreases with seniority and that employment relationships are remarkably durable (Hall, 1982; Topel \& Ward, 1992). Furthermore, the theory supports the

* E-mail: Stijn.Rocher@ua.ac.be; tel: +32 (0) 326543 45; address: S. B. 108, Department of Economics, City Campus, Prinsstraat 13, 2000 Antwerp, Belgium. This paper has benefitted from research grant IAP P6/09 «Higher Education and Research: Organization, Market Interaction and Overall Impact of the Knowledge-Based Era» for financial support. The research was based on the UK Skill Survey (2006) produced by F. Green, D. Gallie, A. Felstead, Y. Zhou. It was collected by BMRB Social Research and supplied by the UK Data Archive. The data are Crown copyright and funded by Economic and Social Research Council, Department for Education and Skills, Department of Trade and Industry, Learning and Skills Council, Sector Skills Development Agency, Scottish Enterprise, Learning and Skills Observatory for Wales East Midlands Development Agency, Highlands and Islands Enterprise, Northern Ireland. Department for Employment and Learning. The author is solely responsible for the content and any views expressed therein. 
finding that wage losses occurring after displacement or unemployment spells are substantially larger for high tenure workers (Topel, 1990; Carrington, 1993). A common foundation to these empirical relationships is the accumulation of firm-specific skills by the worker. Without the dual skill concept, earnings effects of changes in employment relationships are hard to explain.

However, research on industry-specific and occupation-specific skills revealed that the traditional view on human capital is too narrowly focused on firm-specific skills. Overlooking broader concepts of specific skills important to the human capital of workers, may have resulted in upward biased returns to firm tenure. Taking into account industry-specific skills, it is not firm experience, but industry experience that matters most for the wage profile and the relation between wages and seniority (Neal, 1995; Parent, 2000). Similarly, Shaw (1984) demonstrated that occupational tenure is an important determinant of earnings dominating firm-specific experience. Yet, the distinction between industry specificity and occupation specificity of skills is not clear-cut. The reason is that skills might be specific to a set of jobs and rather linked to a combination of certain occupations and industries (Neal, 1995). In an attempt to disentangle industry and occupation effects, Kambourov and Manovskii (2009) consider various methods to identify genuine occupational and industry switches. In turn, they find human capital to be mainly occupation specific with industry or employer tenure having little importance.

Recent research in this strand of the literature aimed at more directly capturing the skill specificities of jobs. The idea is to look at the nature of work and focus at the tasks workers actually do on their jobs. The concept of task-specific skills is closely related to industry-and firm-specific skills which are valued in multiple - but not all - firms. Nevertheless, this skill type differs from both other types in the particular way in which it is defined. This task-oriented approach considers skills to be taskspecific if they are specific to the tasks a worker performs on the job (Gibbons \& Waldman, 2004). This new view on skill specificity provides a natural view on the transferability of human capital between jobs. For example, it seems plausible that when a truck driver switches from one transport company to another, he loses little of his human capital. This is because his truck-driving experience is also of use at the other firm where he will mainly perform identical tasks. The same is true when this truck driver decides to switch industries (e.g. from retail trade to wholesale trade). A truck driver may even easily switch occupations and become a bus driver. Also in this case, his truck-driving skills will be highly valued by his new employer. Only when the task requirement on his new job is very different from the tasks performed as truck driver, the transferability of human capital is expected to be low. For instance, this is true when a truck driver switches to being a farmer or cook, but also after moving to a very different industry. In other words, as opposed to the notion of occupation- or industry-specific skills, task-specific skills not necessarily fully depreciate if a worker moves to another occupation or industry.

1 Controlling for other factors, five years of occupational tenure is estimated to increase wages with 12 to $20 \%$. 
The task approach to jobs and skills has a wide applicability. Gathmann and Schönberg (2010) find that human capital is at least partially transferable across occupations with similar task requirements. Moreover, they show that this new view on human capital is also in line with findings related to job tenure, job reallocation and its wage effects. This concept of task-specific skills also contributed to study the link between the skill use of workers and job task requirements. This resulted in new insights in the relation between technological progress, changing job task requirements and shifts in employment. (Autor et al, 2003; Goos et al, 2009). Furthermore, the task framework proved to be useful in analyzing job task assignment of equally educated native and immigrant workers, the effect of international offshoring on U.S. employment, changes in wage inequality and various other labor market issues. (Cortes, 2008; Peri \& Sparber, 2009; Firpo et al, 2009; Acemoglu \& Autor, 2011).

This paper proposes that task specialization may already begin prior to labor market entry. In addition to general-purpose skills, education also provides field-specific or vocational skills. The choice of subject major is oriented at entering a certain (group of) profession(s). In general, the benefits of these vocational skills are therefore considered to be conditional on working in one of the occupations to which the study major is aimed. ${ }^{2}$ In line with the discussion above, the specificity of vocational skills may, however, be more general than previously thought. This paper investigates the extent to which vocational skills are task-specific. Under this assumption, the benefits of vocational skills are not conditional on working in a specific set of occupations, but on the tasks workers have to perform on the job. Therefore, young workers non-randomly self-select into jobs with certain task-specific skill requirements (and not occupations per se) as suggested by Autor and Handel (2009). In this paper, some implications arising from this conceptual framework are empirically tested using a sample of young higher education graduates. Without going into depth on the precise process of skill acquisition in higher education, graduates from similar fields of study are considered to possess homogeneous task-specific skills. In the remainder of the paper, I address the following:

1. To verify the extent differences in task-specific human capital lead graduates from different majors into jobs with distinct task sets.

2. To investigate the occupational choice of young graduate and look if occupations with similar task content employ comparable shares of graduates from a particular major.

3. To analyze the wage structure of similar occupations. I expect that the earnings of graduates majored in the same field are very similar when their occupations have similar job task requirements.

The structure of the paper is as follows. Having introduced the subject of task-specific skills, the following section will provide a conceptual framework linking skills to tasks. In the third section, I will discuss the data and the methodology to empiri-

2 For an overview, see Grubb (1995). 
cally test our hypotheses concerning job design and job allocation. The results will be discussed in the fourth section and a final section will conclude.

\section{The Conceptual Framework}

The Roy framework proposed by Autor and Handel (2009) captures the non-random occupational choice of workers This framework assumes that workers sort across jobs based on comparative advantage. ${ }^{3}$ Think of an economy in which income-maximizing workers have acquired two task- specific skills $s_{1}$ and $s_{2}$ during education, like numeracy or literacy skills. Such a skill bundle $s(\mathrm{i})=\left\{s_{1 \mathrm{i}}, s_{2 \mathrm{i}}\right\}$ defines the amount of tasks an $i$-type worker can perform on the job. Because education is organized around disciplines, the accumulation of task-specific skills depend on the workers' educational specialization. Therefore, the distribution of skill bundles $\boldsymbol{s}(i)$ across workers is exogenously given by major choice specifying the worker's skill type and is characterized by distribution function $\psi$. Furthermore, also jobs are heterogeneous. Consider a job simply as a set of tasks for the worker. The relative importance of each task in this job task set is assumed to depend on the type of job, called occupation. Accordingly, jobs belonging to another occupation differ in their task-specific skill requirement given by a task load vector $\mathbf{t}(j)=\left\{t_{1 \mathrm{j}}, t_{2 \mathrm{j}}\right\}$ where index $j$ stands for occupation. As a result, the return to the task-specific skill bundle of the worker may differ across jobs. I denote by $P(j)$ the exogenous price level for a unit of output in job of type $j$ and by $y(i, j)$ the output of an $i$-type worker in a $j$-type job given by:

$y(i, j)=\boldsymbol{s}(i) \bullet \mathbf{t}^{T}(j)=s_{1 i} t_{1 j}+s_{2 i} t_{2 j}$

A worker $i$ will select into job $j$ if her income is higher there, that is:

$P(j) y(i, j)>P(k) y(i, k)$

with $j \neq k$

This simple framework can explain the sorting of workers across job tasks. On the one hand, students specialize in certain tasks during education, and on the other hand, task requirements differ across jobs. Therefore, field of study may serve as a good predictor for the tasks workers perform within their jobs. Although many other factors (e.g. preference, ability, condition of the local job market, etc.) determine the actual occupational choice of an individual, the focus in this paper is on the link between subject of study and job content. Without the notion of task-specific skills, this relationship is hard to explain. In the following, I derive three propositions from the conceptual framework which will be tested empirically in the next section. The first proposition relates to the tasks of workers performed on the job.

3 See also Heckman and Sedlacek (1990). 
Proposition 1: The job tasks of young workers are likely to differ significantly among graduates majored in different fields of study.

In this framework, the task specialization of workers already starts during education once they have chosen their field of specialization. Workers majored in the same field of study acquire the same bundle of task-specific skills determining their productivity in every occupation. For that reason, I expect to find that college major choice is an important determinant for the sorting of higher education graduates across occupations and the tasks these young workers perform on their job.

The next proposition is about the transferability of task-specific skills. In reality, we do not observe a one-to-one mapping between field of study and occupation due to several reasons (e.g. search frictions, preferences, ...). Taking into consideration the limitations of the conceptual frame-work, the simple model suggest that as the task load $(\mathbf{t}(j))$ of a job is very different from another $(\mathbf{t}(k))$, it is very unlikely that graduates majored in the same field self-select in both jobs. On the contrary, it is more likely that graduates with the same specialization self-select in jobs with rather similar task loads. This is easily derived from the model as workers with the same specialization doing similar tasks are roughly equally productive, while this is far from true when their task load is very different. Hence, ceteris paribus:

Proposition 2: The more dissimilar the task content of an occupation relative to the occupation of the modal graduate majored in a particular field, the less likely other co-graduates self-select into this occupation.

A last proposition elaborates on this. In discussing the second proposition, I stated that graduates with the same specialization are likely to be roughly equally productive when their task load is similar. Taking the task framework seriously, it permits to say even more. I define the log wage of a worker active in occupation $j$ as:

$\ln w(i, j)=\ln P(j)+\ln y(i, j)$

Given that $\mathrm{P}(j)$ is exogenously determined, it is obvious to derive from the log wage function given by equation (3) that workers majored in the same field are expected to be paid more similarly when doing more similar tasks. This is encapsulated by the following proposition:

Proposition 3: The more similar the task content of an occupation relative to the occupation of the modal graduate majored in a particular field, the better the wage of this modal graduate predicts the wage of a co-graduate in the related occupation.

Although being far from a rigorous testing of the conceptual framework, confirming these three propositions empirically would provide evidence in support of the taskbased Roy assignment model. In order to verify these propositions, I discuss data and methodology that could serve this purpose in the next section. 


\section{Data and methodology}

For the empirical analysis, I merge the Reflex dataset containing in-depth information on qualifications and employment of 70,000 European graduates with the UK Skill survey supplying information on the task content of occupations. ${ }^{4}$ The UK Skill Survey aims to investigate the skill and job requirements of the employed workforce in the British economy. The Survey taken in 2006 consists of 7,762 sampled working individuals representative for the employed population aged 20 to 60 in the UK. The detailed questions on what kind of tasks are important at the current job of the interviewee are used to identify the task content of occupations. This is in fact the task load factor represented by $t(j)$ in the conceptual framework.

The UK Skill Survey contains 42 items that describe the task content of jobs. Individuals report on a 5 point scale how essential a certain task is for their job. I use explanatory factor analysis to reduce the amount of intercorrelated task variables and identify twelve underlying task factors. These factors cover the following task fields: Computer, Literacy, Managing, Numeracy, Nurturing, Physical, Problem solving, Reviewing, Routine, Self-planning, Selling and Teamwork..$^{5}$ Table 1 gives an overview of the task item categorization and reports the task units on which each factor loaded strongly. For further analysis, I select the first component of a principal component analysis on each subgroup of task items as listed in table 1. As a result, each component can easily be interpreted. The scores on the twelve components will serve as measures for the intensity of tasks executed by the worker on his job. The Cronbach's alpha is reported for every generic task component and easily satisfies the acceptable level of 0.7 in almost all cases. This approves my methodology (Nunnally \& Bernstein, 1994).

Table 1: Categorization of Task Items

\begin{tabular}{lc}
\hline Computer $(\alpha=0.7629)$ & Numeracy $(\alpha=0.8124)$ \\
Computer use & Basic arithmetic \\
Complexity of computer use & Arithmetic involving fractions \\
Internet use & Advanced mathematics ans statistics \\
Literacy $(\alpha=0.8787)$ & Nurturing $(\alpha=0.7505)$ \\
Reading written information & Counseling, advising or caring for clients \\
Reading short documents & Dealing with people \\
Reading long documents & Handling feelings of others \\
Write forms, notices or signs & Managing own feelings \\
Write short documents & Physical $(\alpha=0.8158)$ \\
Write long documents & Physical strength \\
Managing $(\alpha=0.8028)$ & Physical stamina \\
Teaching people & Finger and hand dexterity \\
Persuading or influencing others & Knowledge of use or operation of tools \\
Making speeches or presentations & Problemsolving $(\alpha=8638)$ \\
Planning the activities of others & Spotting problems or faults \\
& \\
\hline 4 & For an in-depth analysis of the Reflex project see Allen and van der Velden (2007). Analogously, see \\
Felstead et al. (2007) for more detail on the UK Skill Survey. \\
5 These factors are largely similar as the one indentified by Green (2009) using the same dataset.
\end{tabular}




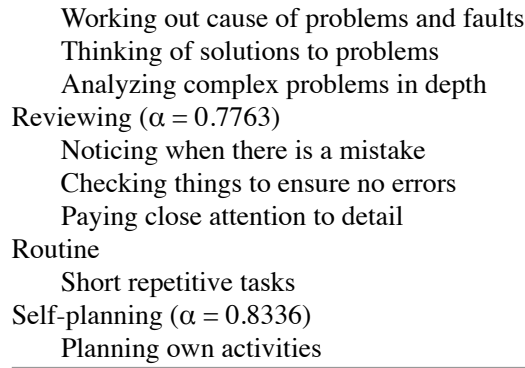

Working out cause of problems and faults Thinking of solutions to problems Analyzing complex problems in depth Reviewing ( $\alpha=0.7763)$

Noticing when there is a mistake

Checking things to ensure no errors

Paying close attention to detail Routine

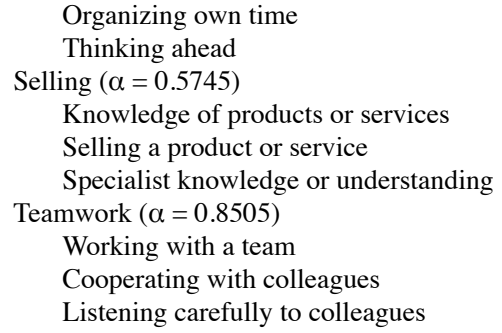

This information on the tasks workers actually do on their job is merged with the Reflex dataset. This latter dataset is particularly useful as the major choice and job related information is reported for a large group of graduates interviewed in 2005, five years after graduation. I combine the two datasets at the 3-digit level ISCO coding. ${ }^{6}$ Following the conceptual framework, this presumes that workers perform the same tasks when employed in the same occupation. Furthermore, the task content of jobs is identified from a sample of British workers. In assuming that also workers from different countries do the same tasks in the same occupation, this exercise makes a strong assumption. For instance, differences in job regulation may result in very different task loads in identical occupations across countries. The lack of internationally comparable data on tasks, necessitates me to make this additional simplifying assumption. Therefore, I also report the findings solely for the reduced sample of British graduates. Finally, 21,064 graduates employed in 80 different occupations are matched to task information about their jobs. ${ }^{7}$ For this sample of graduates, the Reflex dataset provides detailed information on the field of study. Based on this information, the graduates are grouped into 14 different disciplines. These broad categories make sure that there are enough observations for each major-country cell which is necessary for robust results. The graduates originate from ten different European countries. An overview is given in table A1 in appendix.

In order to test the second and third proposition, I need to quantify to which degree the task content of two occupations are similar. The mahalanobis distance (MD) can serve this purpose and is given by the following formula:

$$
M D_{x}^{y}=\sqrt{(\mathbf{t}(x)-\mathbf{t}(y))^{T} \Sigma^{-1}(\mathbf{t}(x)-\mathbf{t}(y))}
$$

In expression (4) $\mathbf{t}(x)$ and $\mathbf{t}(y)$ indicate the task load vectors of two random occupation $x$ and $y$ taken from a task vector distribution with variance-covariance matrix $\Sigma$. The MD is in fact the weighted Euclidean distance where the weights are determined by $\Sigma^{-1}$ and for that reason superior in analysis of correlated data. To reduce computational problems faced by MD like multicollinearity and measurement errors, I opt

6 The International Standard Classification of Occupations (ISCO) is organised by the ILO and is occasionally updated. For our analysis, the version of 1988 is used. For more info: www.ilo.org.

7 Not all countries in the original REFLEX dataset reported wage information or 3-digit ISCO codings. This explains the large drop in observations. 
to use the 12-dimensional task load vector as reported in table 1 instead of all 42 task items. The distances between the task loads of the graduates are rescaled such that the largest distance observed in the sample equals one. The value equals zero for occupations that involve an identical task package and approaches one if the task content is far from similar. The average distance is 0.232 with a standard deviation of 0.221 . Table 2 reports an illustration of the distance concept. I report computed distance values to the reference occupation «architects and engineers» (ISCO 214) for ten different occupations. I obtain that a related occupation is «physical and engineering science technicians» (ISCO 311), while an unconnected occupation is «street vendors and related workers» (ISCO 911). These plausible findings convince that the distance concept makes sense.

Table 2 Close and distant occupations

\begin{tabular}{lr}
\hline Architects and engineers (214) & Distance \\
Close occupations & 0.183 \\
Physical and engineering science technicians (311) & 0.230 \\
Other department managers (123) & 0.230 \\
Material-, recording and transport clerks (413) & 0.242 \\
Physicists, chemists and related professionals (211) & 0.251 \\
Metal-and mineral products machine operators (821) & 0.587 \\
Distant occupations & 0.607 \\
Assemblers (828) & 0.617 \\
Wood treaters, cabinet-makers and related trades workers (742) & 0.637 \\
Library, mail and related clerks (414) & 0.697 \\
Textile-, fur- and leather-products machine operators (826) & \\
Street vendors and related workers (911) &
\end{tabular}

Notes: based on author's calculations; ISCO '88 coding between parentheses

\section{Results}

The data described in the previous section will be used to test the three propositions formulated in section 2. First, I investigate the degree to which graduates from different disciplines self-select into jobs with very different task content. The importance of a particular task $T_{i m c}$ on the job of a young graduate $i$ with specialization $m$ from country $c$ is proxied by the task factor scores as previously discussed This variable will serve as the regressand in the following specification:

$T_{i m c}=\beta_{0}+\boldsymbol{X}_{m}^{T} \boldsymbol{\beta}_{1}+\boldsymbol{Z}_{c}^{T} \boldsymbol{\beta}_{2}+u_{m c}+\varepsilon_{i m c}$

Here, $\boldsymbol{X}_{m}$ is a vector of major dummies corresponding to all 14 distinguished specializations as listed in table $\mathrm{A} 1 . \boldsymbol{Z}_{c}$ is a vector of country controls. The empirical specification accounts for major-country specific error $u_{m c}$. Correlation within these clusters might arise due to differences in task-specialization across country clusters. Table 3 reports estimates from the regression specified in equation (5) for 6 out of 12 task fields. 
Table 3: Job tasks by field of study

\begin{tabular}{|c|c|c|c|c|c|c|}
\hline & (1) & (2) & (3) & (4) & (5) & (6) \\
\hline Dependent Variable & Literacy & Numeracy & Nurturing & $\begin{array}{l}\text { Problem- } \\
\text { solving }\end{array}$ & $\begin{array}{c}\text { Re- } \\
\text { viewing }\end{array}$ & Selling \\
\hline $\begin{array}{l}\text { Economics, business } \\
\text { and administration }\end{array}$ & $\begin{array}{l}\text { Reference } \\
\text { group }\end{array}$ & $\begin{array}{l}\text { Reference } \\
\text { group }\end{array}$ & $\begin{array}{l}\text { Reference } \\
\text { group }\end{array}$ & $\begin{array}{l}\text { Reference } \\
\text { group }\end{array}$ & $\begin{array}{l}\text { Reference } \\
\text { group }\end{array}$ & $\begin{array}{l}\text { Reference } \\
\text { group }\end{array}$ \\
\hline $\begin{array}{l}\text { Agriculture, forestry } \\
\text { and fishery }\end{array}$ & $\begin{array}{c}0.097 \\
(0.144)\end{array}$ & $\begin{array}{c}0.116 \\
(0.107)\end{array}$ & $\begin{array}{c}-0.413 * * \\
(0.139)\end{array}$ & $\begin{array}{c}0.362 * * \\
(0.055)\end{array}$ & $\begin{array}{c}0.355 * * \\
(0.101)\end{array}$ & $\begin{array}{l}0.254 * * \\
(0.055)\end{array}$ \\
\hline Arts & $\begin{array}{c}-0.457 * * \\
(0.072)\end{array}$ & $\begin{array}{c}-0.700 * * \\
(0.082)\end{array}$ & $\begin{array}{c}-0.177 * * \\
(0.066)\end{array}$ & $\begin{array}{c}-0.346^{* *} \\
(0.062)\end{array}$ & $\begin{array}{l}-0.211 * * \\
(0.079)\end{array}$ & $\begin{array}{l}-0.174 \\
(0.092)\end{array}$ \\
\hline Education & $\begin{array}{c}0.595 * * \\
(0.088)\end{array}$ & $\begin{array}{c}0.008 \\
(0.087)\end{array}$ & $\begin{array}{c}0.958 * * \\
(0.069)\end{array}$ & $\begin{array}{c}-0.464 * * \\
(0.036)\end{array}$ & $\begin{array}{c}-0.516^{* *} \\
(0.044)\end{array}$ & $\begin{array}{l}-1.271 * * \\
(0.073)\end{array}$ \\
\hline $\begin{array}{l}\text { Engineering, building } \\
\text { and architecture }\end{array}$ & $\begin{array}{l}-0.102 \\
(0.055)\end{array}$ & $\begin{array}{c}0.716 * * \\
(0.070)\end{array}$ & $\begin{array}{c}-0.800 * * \\
(0.057)\end{array}$ & $\begin{array}{c}0.639 * * \\
(0.036)\end{array}$ & $\begin{array}{c}0.217 * * \\
(0.034)\end{array}$ & $\begin{array}{c}0.102 \\
(0.052)\end{array}$ \\
\hline Health & $\begin{array}{c}0.101 \\
(0.103)\end{array}$ & $\begin{array}{c}-0.399 * * \\
(0.079)\end{array}$ & $\begin{array}{c}0.957 * * \\
(0.079)\end{array}$ & $\begin{array}{c}0.634 * * \\
(0.067)\end{array}$ & $\begin{array}{c}0.804 * * \\
(0.075)\end{array}$ & $\begin{array}{c}0.760 * * \\
(0.091)\end{array}$ \\
\hline Humanities & $\begin{array}{c}0.100 \\
(0.068)\end{array}$ & $\begin{array}{c}-0.631 * * \\
(0.100)\end{array}$ & $\begin{array}{c}0.349 * * \\
(0.075)\end{array}$ & $\begin{array}{c}-0.611^{* *} \\
(0.064)\end{array}$ & $\begin{array}{c}-0.616^{* *} \\
(0.090)\end{array}$ & $\begin{array}{c}-0.558 * * \\
(0.052)\end{array}$ \\
\hline Law & $\begin{array}{l}1.475 * * \\
(0.084)\end{array}$ & $\begin{array}{c}-0.614 * * \\
(0.069)\end{array}$ & $\begin{array}{c}0.107 \\
(0.064)\end{array}$ & $\begin{array}{c}0.807 * * \\
(0.055)\end{array}$ & $\begin{array}{c}0.693 * * \\
(0.067)\end{array}$ & $\begin{array}{c}-0.468 * * \\
(0.047)\end{array}$ \\
\hline Linguistics & $\begin{array}{c}0.320 * * \\
(0.087)\end{array}$ & $\begin{array}{c}-0.453 * * \\
(0.070)\end{array}$ & $\begin{array}{c}0.439 * * \\
(0.078)\end{array}$ & $\begin{array}{c}-0.347 * * \\
(0.068)\end{array}$ & $\begin{array}{c}-0.305 * * \\
(0.072)\end{array}$ & $\begin{array}{c}-0.530 * * \\
(0.062)\end{array}$ \\
\hline $\begin{array}{l}\text { Mathematics, statistics } \\
\text { and computing }\end{array}$ & $\begin{array}{c}-0.283 * * \\
(0.087)\end{array}$ & $\begin{array}{c}0.300 * * \\
(0.078)\end{array}$ & $\begin{array}{c}-0.635^{* *} \\
(0.088)\end{array}$ & $\begin{array}{c}0.994 * * \\
(0.082)\end{array}$ & $\begin{array}{c}0.295 * * \\
(0.060)\end{array}$ & $\begin{array}{c}0.206^{* *} * \\
(0.075)\end{array}$ \\
\hline Personal services & $\begin{array}{l}-0.030 \\
(0.123)\end{array}$ & $\begin{array}{l}-0.087 \\
(0.112)\end{array}$ & $\begin{array}{c}0.182 \\
(0.113)\end{array}$ & $\begin{array}{c}-0.213^{*} \\
(0.083)\end{array}$ & $\begin{array}{c}-0.225^{* *} \\
(0.064)\end{array}$ & $\begin{array}{l}-0.209 \\
(0.112)\end{array}$ \\
\hline Science & $\begin{array}{c}0.336 * * \\
(0.069)\end{array}$ & $\begin{array}{c}0.306 * * \\
(0.106)\end{array}$ & $\begin{array}{c}-0.494 * * \\
(0.103)\end{array}$ & $\begin{array}{c}0.593 * * \\
(0.089)\end{array}$ & $\begin{array}{c}0.396 * * \\
(0.083)\end{array}$ & $\begin{array}{l}-0.047 \\
(0.063)\end{array}$ \\
\hline $\begin{array}{l}\text { Social and behavioral } \\
\text { science }\end{array}$ & $\begin{array}{c}0.503 * * \\
(0.073)\end{array}$ & $\begin{array}{c}-0.814 * * \\
(0.111)\end{array}$ & $\begin{array}{c}0.465 * * \\
(0.080)\end{array}$ & $\begin{array}{l}-0.038 \\
(0.043)\end{array}$ & $\begin{array}{l}-0.066 \\
(0.050)\end{array}$ & $\begin{array}{c}-0.249 * * \\
(0.056)\end{array}$ \\
\hline Social services & $\begin{array}{c}0.612 * * \\
(0.149)\end{array}$ & $\begin{array}{c}-1.317 * * \\
(0.142)\end{array}$ & $\begin{array}{l}1.006^{* * *} \\
(0.099)\end{array}$ & $\begin{array}{l}-0.078 \\
(0.090)\end{array}$ & $\begin{array}{c}-0.306^{* *} \\
(0.084)\end{array}$ & $\begin{array}{c}-0.259 * \\
(0.114)\end{array}$ \\
\hline F (major) & 67.50 & 97.18 & 241.12 & 106.24 & 56.22 & 86.21 \\
\hline $\mathrm{p}$-value & 0.000 & 0.000 & 0.000 & 0.000 & 0.000 & 0.000 \\
\hline $\mathrm{R}^{2}$ & 0.168 & 0.306 & 0.414 & 0.231 & 0.166 & 0.271 \\
\hline
\end{tabular}

Notes: $\mathrm{N}=20,046$; robust std. errors clustered at major-country level in parentheses; stars indicate significance levels: ** $\mathrm{p}<0.01, * \mathrm{p}<0.05$

From this table, it is clear that graduates majored in different fields perform significantly different tasks on their job. ${ }^{8}$ Unsurprisingly, «linguistics» graduates perform more literacy tasks on the job relative to graduates in «economics, business and administration», while they spend less time on numeracy and problem-solving tasks. In

8 As task factor scores are standardized, the coefficients can be easily compared. 
contrast, «mathematics, statistics and computing» graduates spend even more time on arithmetic, problem analysis and other numeracy and problem-solving tasks compared to the reference group. On the other hand, literacy tasks are less important for these graduates. A statistical test of the first proposition consists of evaluating the Wald test for joint significance for the group of major identifiers. In each specification, the F-statistic is very high resulting in p-values below $1 \%$. Therefore, I conclude that proposition 1 holds. The educational specialization of graduates is an important determinant for the job tasks of these graduates. This suggests that at least part of the human capital acquired during education is task-specific.

The assessment of the last two propositions makes use of the distance concept introduced in last section. For every major-country cluster, I identify the most popular occupational choice. The distance to the major-country modal occupation is computed for all individuals in the particular cluster. The motivation to take the modal occupation as reference is that it is assumed to be a good proxy for the task preference of graduates within the major-country cluster. Next, I empirically test the second proposition. This proposition suggest that it is likely that graduates majored in the same field of study end up doing similar job tasks. This is a natural result from the assumption that graduates acquire task-specific skills during education and that these task-specific skills are not equally productive in every job. Due to this selfselection based on comparative advantage in tasks, I therefore expect to find that the further an occupation is located from the modal occupation of a particular majorcountry cluster, the less graduates from this cluster are employed in that occupation. In regression equation (6) below,

share $_{i m c}=\beta_{0}+\beta_{1}$ distance $_{i m c}+\mathbf{Z}_{m c}^{T} \boldsymbol{\beta}_{2}+u_{m c}+\varepsilon_{\text {imc }}$

share $_{i m c}$ defined as the share of co-graduates in the same occupation as graduate $i$, is the dependent variable. The variable distance $_{\text {imc }}$ is defined as described above and $\mathbf{Z}_{m c}$ contains major and country controls. The graduates in the modal occupation were dropped in the OLS estimation, because the largest value of share $_{i m c}$ is by construction at the modal occupation. Here, also the value of distance ${ }_{i m c}$ will be smallest (equal to zero). Table 4 provides the estimate of $\beta_{1}$ for three different specifications. The first specification is without major-country controls $\left(\boldsymbol{\beta}_{2}=0\right)$. The second specification is the estimation of equation (6). The last specification interacts distance ${ }_{\text {imc }}$ with country dummies. Only the $\beta_{1}$ estimate for the UK is presented for reasons given in section $3 .{ }^{9}$ All standard errors are robust and clustered at the major-country level. The estimate of $\beta_{1}$ is negative at the $1 \%$ significance level in all specifications. Hence, distance negatively influences the occupational choice of graduates. This is in support of my second proposition.

9 The Wald test on the joint significance of the country interactions is not significant. Thus, the estimate of $\beta_{1}$ does not differ statistically between countries. 
Table 4: Share of co-graduates decreasing in distance

\begin{tabular}{lccc}
\hline & $(1)$ & $(2)$ & $(3)$ \\
Dependent variable & Share & Share & Share \\
\hline Distance & $-0.116^{* *}$ & $-0.205^{* *}$ & $-0.130^{* *}$ \\
& $(0.023)$ & $(0.031)$ & $(0.023)$ \\
Controls & no & yes & yes \\
Country interactions & no & no & yes \\
F (interaction) & & & 1.07 \\
p-value & & & 0.388 \\
& & & \\
Observations & 12,142 & 12,142 & 12,142 \\
$\mathrm{R}^{2}$ & 0.053 & 0.328 & 0.344 \\
\hline
\end{tabular}

Notes: robust standard errors clustered at major-country level in parentheses; stars indicate significance levels: ** p $<0.01$, $* \mathrm{p}<0.05$; major-country controls; country interaction: all explanatory variables interacted with country ID (only UK (ref.) \& F-tests of interactions shown)

The last proposition states that workers majored in the same field are expected to be paid more similarly when doing more similar tasks. Therefore, a good predictor of the wage of a single graduate is average earnings of co-graduates in a related occupation. I verify this by using the average of log gross hourly wages in the modal occupation (ln hrwage_mod ${ }_{m c}$ ) as reference. Hence, the empirical specification becomes:

$$
\begin{aligned}
& \ln \text { hrwage }_{i m c}=\beta_{0}+\beta_{1} \ln \text { hrwage__mod }{ }_{m c}+ \\
& \beta_{2} \text { distance }_{i m c}+\beta_{3} \text { interaction }_{i m c}+\mathbf{Z}_{m c}{ }^{T} \boldsymbol{\beta}_{4}+u_{m c}+\varepsilon_{i m c}
\end{aligned}
$$

Under the null hypothesis, the closer the task load of a graduate with respect to that of co-graduates in the modal occupation, the more similar the pay. In other words, the estimate of the interaction coefficient between distanceimc and ln hrwage_mod$\mathrm{mc}$ is expected to be negative. That is indeed what table 5 reveals. As a robustness check, I follow a similar strategy as above. Only the first specification does not control for major-country effects $\left(\boldsymbol{\beta}_{4}=0\right)$. In specification (3), all explanatory variables are interacted with a country identifier. The country of reference is the UK and only the estimated coefficients for this country are reported. In all three models, the interaction effect is significantly negative. Remark that the joint significance test of the country-interaction effects reveals that the estimate of $\beta_{3}$ does not significantly differ between countries. Thus, also the third proposition is not rejected. 
Table 5: Correlation between the modal wage and individual wages decreasing in distance

\begin{tabular}{lccc}
\hline Dependent variable & $(1)$ & $(2)$ & $(3)$ \\
ln hrwage & ln hrwage \\
\hline ln hrwage_mod & $1.008^{* *}$ & $0.749^{* *}$ & $0.823^{* *}$ \\
& $(0.007)$ & $(0.025)$ & $(0.033)$ \\
Distance & $0.605^{* *}$ & $0.387 *$ & $3.606^{* *}$ \\
& $(0.185)$ & $(0.194)$ & $(0.954)$ \\
ln hrwage_mod*distance & $-0.303^{* *}$ & $-0.205^{* *}$ & $-1.401^{* *}$ \\
& $(0.074)$ & $(0.075)$ & $(0342)$ \\
& & & yes \\
Controls & no & yes & yes \\
Country interaction & no & & $112.35^{* *}$ \\
F-test (ln hrwage_mod*country) & & & $6.65^{* *}$ \\
F-test (distance*country) & & & 1.88 \\
F-test (interaction*country) & & 18,264 & 18,264 \\
& & 0.703 & 0.712 \\
Observations & 18,264 & & \\
$\mathrm{R}^{2}$ & 0.678 & & \\
\hline
\end{tabular}

Notes: stars indicate significance levels: $* * \mathrm{p}<0.01, * \mathrm{p}<0.05$; robust standard errors clustered at country level in parentheses; major-country controls; country interaction: all explanatory variables interacted with country ID (only UK (ref.) and F-tests of interactions shown)

\section{Conclusion}

The notion of task-specific skills is a promising avenue for further research on the specificity of human capital. Yet, little is known about how skills relate to job tasks. The theoretical framework on tasks assumes that workers sort across job tasks based on comparative advantage. Since income-maximizing workers have heterogenous task-specific skill endowments, they self-select into various occupations and end up doing very different tasks at their job. In this paper, I suggest that task-specialization might already occur prior to labor market entry. At higher education, students choose a college major aspiring to find employment in this field after graduation. Therefore, they likely acquire task-specific skills preparing them for these jobs. I empirically explore three propositions and find that:

(i) major choice is an important determinant of what tasks workers do at their job;

(ii) graduates majored in the same field self-select into occupations with similar task content;

(iii) also the wages of these graduates is correlated strongest when they do similar tasks. 
To sum up, it seems that students accumulate task-specific skills during education and that task-specialization matters for occupational choice. This supports additional evidence in favor of the task framework.

The scope of this paper is limited to illustrating the value of the task approach in analysing occupational choice. There remain many interesting tracks for further elaboration on this topic using detailed data on job tasks. One involves to relate the degree of vocational orientation of subject majors to task specialization. Do students with general degrees have a wider task span than students with vocational degrees? Another fruitful area for future research may be to study the differences in the extent of in-subject working by field of study and the effect of task mismatch e.g. on wages or job satisfaction. The task approach could also contribute in understanding the large earnings differences between different occupations.

\section{References}

Acemoglu, D. \& Autor, D. (2011). Skills, tasks and technologies: Implications for employment and earnings, In: O. Ashenfelter \& D. Card (Eds.): Handbook of labor economics, vol. 4. Amsterdam: Elsevier

Allen, J. \& van der Velden, R. (2007). The flexible professional in the knowledge society: General results of the REFLEX project. Maastricht: University, Research Centre for Education and the Labour Market

Autor, D. \& Handel, M. (2009). Putting tasks to the test: human capital, job tasks and wages. Cambridge, Mass. NBER Working Paper, nr. 15116

Autor, D.; Levy, F. \& Murnane, R. (2003). The skill content of recent technological change: An empirical exploration, Quarterly Journal of Economics, vol. 118 (4), pp. 1279-1333

Becker, G. (1964). Human Capital: A theoretical and empirical analysis, with special reference to education. New York, Columbia University Press

Brown, J. (1989) Why do wages increase with tenure? On-the-job training and life-cycle wage growth observed within firms, American Economic Review, 79(5), pp. 971-91

Carrington, W. (1993). Wage losses for displaced workers: Is it really the firm that matters? Journal of Human Resources, 28(3), pp. 435-462

Cortes, P. (2008). The effect of low-skilled immigration on U.S. prices: Evidence from CPI data, Journal of Political Economy, 116(3), 381-422

Felstead, A.; Gallie, D.; Green, F. \& Zhou, Y. (2007). Skills at work, 1986 to 2006. Oxord: University of Oxford, SKOPE

Firpo, S.; Fortin, N. \& Lemieux, T. (2009). Occupational tasks and changes in the wage structure [unpublished]

Gathmann, C. \& Schönberg, U. (2010). How general is human capital? A task-based approach, Journal of Labor Economics, vol. 28(1), pp. 1-49

Gibbons, R. \& Waldman, M. (2004). Task-specific human capital, American Economic Review, vol. 94(2), pp. 203-207

Goos, M., Manning, A. \& Salomons, A. (2009). Job polarization in Europe, American Economic Review: Papers \& Proceedings, vol. 99(2), pp. 1-9

Green, F. (2009). Employee Involvement, Technology and Job Tasks. London: National Institute of Economic and Social Research. NIESR Discussion Papers, no. 326

Grubb, W. (1995). Education through occupations in American high schools. New York: Teachers College Press

Hall, R. (1982). The importance of lifetime jobs in the U.S. economy, American Economic Review, vol. 72(4), pp. 716-724

Heckman, J. \& Sedlacek, G. (1990). Self-selection and the distribution of hourly wages, Journal of Labor Economics, vol. 8(1), pp. S329-S363

Kambourov, G. \& Manovskii, I. (2009). Occupational specificity of human capital, International Economic Review, vol. 50(1), pp. 63-115 
Mincer, J. (1974). Schooling, experience, and earnings. New York: Columbia University Press

Neal, D. (1995). Industry-specific human capital: Evidence from displaced workers, Journal of Labor Economics, vol. 13(4), pp. 653-677

Nunnally, J. C., \& Bernstein, I. H. (1994). Psychometric theory, (3 ${ }^{\text {rd }}$ ed). New York: McGraw-Hill

Parent, D. (2000), Industry-specific capital and the wage profile: evidence from the National longitudinal survey of youth and the panel study of income dynamics, Journal of Labor Economics, vol. 18(2), pp. 306-323

Peri, G. \& Sparber, C. (2009). Task specialization, immigration, and wages, American Economic Journal: Applied Economics, vol. 1(3), pp. 135-169

Shaw, K. (1984). A formulation of the earnings function using the concept of occupational investment, Journal of Human Resources, vol. 19(3), pp. 319-340

Topel, R. (1990). Specific capital and unemployment: Measuring the costs and consequences of job loss, Carnegie-Rochester Conference Series on Public Policy, vol. 33, pp. 181-214

Topel, R. (1991). Specific capital, mobility, and wages: Wages rise with job seniority, Journal of Political Economy 99 (1991), pp. 145-176

Topel, R. \& Ward, M. (1992). Job mobility and the careers of young men, The Quarterly Journal of Economics, vol. 107(2), pp. 439-479 


\section{Appendix}

Table A1: Descriptive statistics

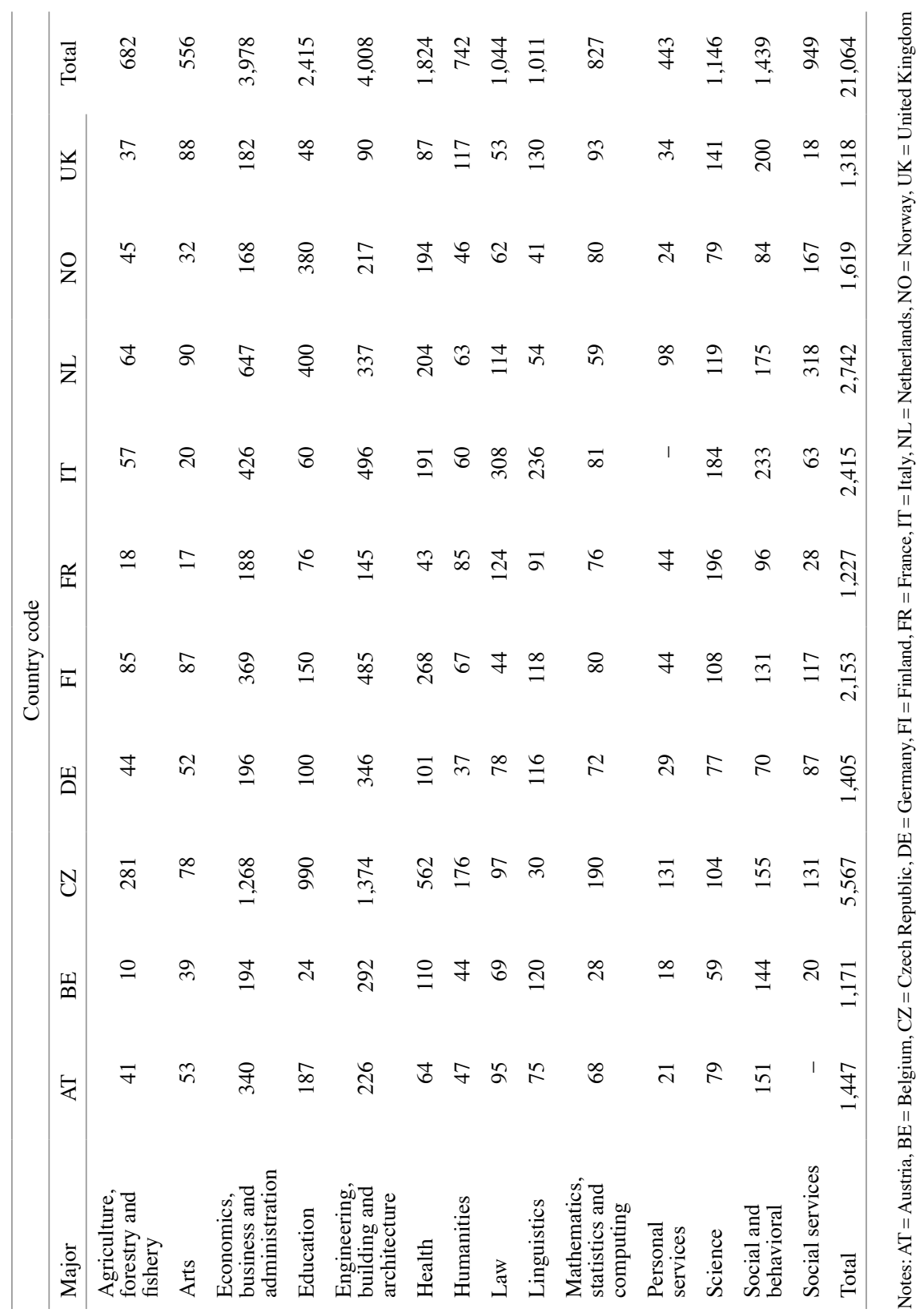

